\title{
Co-Administration of a Plasmid Encoding CD40 or CD63 Enhances the Immune Responses to a DNA Vaccine Against Bovine Viral Diarrhea Virus in a Mouse Model
}

\section{Leng Dongze \\ Iwate University: Iwate Daigaku \\ Shinji Yamada \\ Iwate University: Iwate Daigaku \\ Yusuke Chiba \\ Iwate University: Iwate Daigaku}

\section{Syuji Yoneyama}

Iwate University: Iwate Daigaku

\section{Yusuke Sakai}

Iwate University: Iwate Daigaku

Hirokazu Hikono

Teikyo University of Science: Teikyo Kagaku Daigaku

Kenji Murakami ( $\nabla$ muraken@iwate-u.ac.jp)

Iwate University https://orcid.org/0000-0003-3813-818X

\section{Research Article}

Keywords: bovine viral diarrhea virus, CD40, CD63, DNA vaccine, E2

Posted Date: December 17th, 2021

DOI: https://doi.org/10.21203/rs.3.rs-1173189/v1

License: (a) (i) This work is licensed under a Creative Commons Attribution 4.0 International License. Read Full License 


\section{Abstract}

Bovine viral diarrhea virus (BVDV) causes substantial economic losses in the livestock industry worldwide. Plasmids encoding the BVDV E2 protein are potential DNA vaccines against BVDV, but their immunogenicity has been insufficient. Here, we investigated the adjuvant effect of CD40 and CD63 on the immune responses to a BVDV E2 DNA vaccine in a mouse model. We constructed pUMVC4a-based plasmids encoding the BVDV E2 protein (pE2), mouse CD40 (pCD40), or mouse CD63 (pCD63). Protein expression by each plasmid was confirmed through Western blot analysis and immunofluorescence staining of cultured cell lines. BALB/c mice were immunized intradermally twice with pE2 in combination with, or without, pCD40 or pCD63, with 3 weeks between the two doses. pE2 with pCD40 induced significantly higher neutralizing antibody titers against BVDV than $\mathrm{pE} 2$ alone. Furthermore, $\mathrm{pE} 2$ with pCD40 or pCD63 induced significantly increased lymphocyte proliferation and IFN-ץ production in response to BVDV ex vivo, compared with E2 alone. These results suggest that a plasmid encoding CD40 or CD63 can be used as an adjuvant to enhance immune responses to DNA vaccines against BVDV.

\section{Introduction}

Bovine viral diarrhea virus (BVDV), which belongs to the Flaviviridae family and genus Pestivirus, is an enveloped single-stranded positive-sensed RNA virus [1, 2]. BVDV is mainly a pathogen of cattle, but it also infects buffaloes, deer, pigs, sheep, goats, yaks, and wild ruminants [3]. The clinical manifestations of BVDV are acute infection, fetal infection, and mucosal disease. Fetal infections are particularly associated with congenital malformations and abortion. BVDV can be transmitted to newborn calves through the placenta, potentially resulting in persistent infection in calves that can transmit the virus throughout their lives [4-6]. BVDV infection has caused huge economic losses to the global animal husbandry industry through reduced milk production, abortions, and the decreased lifespan of infected animals [7]. Fatality losses due to BVDV have been estimated at US\$5.26 per infected animal, with performance losses at US\$88.26 per infected animal [8].

Vaccination is used to control BVDV infection [9]. However, several problems exist in the current BVDV vaccines. Although modified live virus (MLV) vaccines induce greater immune responses and longer duration of protection than killed virus (KV) vaccines, MLV vaccines are at risk of generating a pathogenic revertant and vertical transmission in pregnant cattle. KV vaccines do not carry such a risk, but they requires multiple immunizations to achieve protection against infection [4]. Furthermore, unlike MLV vaccines, $\mathrm{KV}$ vaccines do not induce cell-mediated immune responses efficiently [10-12].

DNA vaccines are plasmids that encode protective antigens. Compared with conventional MLV and KV vaccines, DNA vaccines are more stable, easier to manufacture, and safer during handling [13]. DNA vaccines induce not only humoral immune responses but also cell-mediated immune responses by directly expressing antigens on antigen-presenting cells [14]. DNA vaccines have been investigated for various applications, including therapy of cancer [15], allergies [16], autoimmunity, [17] and infectious diseases [18]. Some DNA vaccines have been approved for veterinary use, including those against West 
Nile virus in horses, canine melanoma, growth hormone releasing hormone in pigs, and infectious hematopoietic necrosis virus in fish [19-23]. DNA vaccines encoding BVDV E2 protein have been shown to induce virus neutralizing antibodies [24-26]. However, their immunogenicity remains insufficient.

The co-stimulatory molecule CD40 is a member of the tumor necrosis factor (TNF) receptor superfamily and is constitutively expressed on the surfaces of diverse immune and non-immune cell types, including B cells, dendritic cells, macrophages, and endothelial cells [27]. CD40 directly binds TRAF2, TRAF3, TRAF5, and TRAF6 and indirectly associates with TRAF1 [28]. These interactions result in transcription factor activation, activation of mitogen and stress-activated protein kinase cascades, cytokine secretion, proliferation, differentiation of B cells into Ig-secreting plasma cells, and formation of humoral memory. Anti-CD40 antibodies have enhanced immune responses to DNA or synthetic peptide vaccines in mouse models [29-32], and the co-administration of plasmids encoding CD40 has enhanced humoral and cellular immune responses to DNA vaccines [33-35].

CD63 is a member of the tetraspan family and is expressed on various cellular membranes, including extracellular vesicles. Also known as lysosomal-associated membrane protein 3, CD63 is involved in antigen presentation [36-38]. CD63 represents an activation-induced reinforcing element, the triggering of which promotes sustained and efficient T-cell activation and expansion [39]. A plasmid encoding an ovalbumin (OVA) - CD63 fusion protein enhanced cellular immune responses to OVA, whereas coadministration of a plasmid encoding CD63 did not enhance cellular immune responses to the OVA encoded by another plasmid [40].

In this study, we used a mouse model to investigate whether co-administration of a plasmid encoding CD40 or CD63 enhanced immune responses to a BVDV E2 DNA vaccine.

\section{Materials And Methods}

\section{Cell lines and virus}

MDBK and HEK-293T cells were cultured in Dulbecco's Modified Eagle's Medium (Nissui, Tokyo, Japan). Bovine fetal muscle cells within 20 passages were cultured in Eagle's Minimal Essential Medium (Nissui) supplemented with $10 \%$ tryptose phosphate broth. CHO-K1 and P3U1 cells were cultured in RPMI 1640 medium (Nacalai Tesque, Kyoto, Japan). These three media were supplemented with $5 \%$ heat-inactivated fetal bovine serum (FBS; Thermo Fisher Scientific, Waltham, MA, USA), 100 units/mL penicillin (Nacalai Tesque), $100 \mu \mathrm{g} / \mathrm{mL}$ streptomycin (Nacalai Tesque), and $2 \mathrm{mM} \mathrm{I-glutamine} \mathrm{(Thermo} \mathrm{Fisher} \mathrm{Scientific).}$ Cells were cultured at $37^{\circ} \mathrm{C}$ in a humidified atmosphere containing $5 \% \mathrm{CO}_{2}$ and $95 \%$ air. The FBS used was confirmed to be free of anti-BVDV antibodies by using a virus neutralizing assay (described below).

BVDV 1 (Nose strain; GenBank accession no. AB078951) was propagated in MDBK cells. At 72 to $96 \mathrm{~h}$ after infection at an $\mathrm{MOI}$ of 0.1 to 0.01 , the cells underwent three freeze-thaw cycles; cell debris were removed by centrifugation at $1710 \times \mathrm{g}$ for $15 \mathrm{~min}$ at $4^{\circ} \mathrm{C}$. The virus titer was determined according to the 
$50 \%$ tissue culture infective dose $\left(\mathrm{TCID}_{50}\right)$ for bovine fetal muscle cells in 96 -well flat culture plates. The virus stock was stored at $-70^{\circ} \mathrm{C}$ until use.

\section{Construction of DNA plasmids}

For the construction of plasmids encoding mouse CD40 (pCD40) or CD63 (pCD63), total RNA was extracted from kidney or splenocytes, respectively, of BALB/c mice by using TRIzol reagent (Thermo Fisher Scientific). For construction of a plasmid encoding BVDV E2 protein ( $p E 2)$, TRIzol-LS reagent (Thermo Fisher Scientific) was used to extract total RNA from the culture supernatant of MDBK cells infected with BVDV 1 Nose strain. A PrimeScript RT Reagent Kit (Takara Bio, Shiga, Japan) was used for reverse transcriptions of mRNA or the viral RNA genome. cDNA was synthesized by incubating at $37^{\circ} \mathrm{C}$ for 15 min and $85^{\circ} \mathrm{C}$ for $5 \mathrm{~s}$ in a T100 Thermal Cycler (BioRad, Hercules, CA, USA).

The coding sequence of the mouse CD40 or CD63 gene was amplified through PCR by using a specific primer set. The primer sequences were (restriction enzyme sites are underlined): CD40 forward primer (Apal), 5'-GTAGGGCCCGCGATGGTGTCTTTGCCTCGGCTGTG-3'; CD40 reverse primer (Xbal), 5'GCTCTAGAGCTCAGACCAGGGGCCTCAAGG-3'. CD63 forward primer (EcoRI), 5'GCGGAATTCACCACCATGGCGGTGGAAGGAGGAAT-3'; and CD63 reverse primer (ㅁpal), 5'ATGGGGCCCCCCCTACATTACTTCATAGCCAC-3'. Reaction mixtures consisted of $40 \mathrm{ng} / 1 \mu \mathrm{L}$ of cDNA, 1 $\mu \mathrm{L}$ each of $10 \mu \mathrm{M}$ forward and reverse primers, $5 \mu \mathrm{L}$ of KOD One (Toyobo, Osaka, Japan), and $2 \mu \mathrm{L}$ of sterilized ultrapure water. Amplification wass performed under the following conditions: initial denaturation at $94^{\circ} \mathrm{C}$ for $2 \mathrm{~min}$, followed by 30 cycles of denaturation at $98^{\circ} \mathrm{C}$ for $10 \mathrm{~s}$, annealing at $60^{\circ} \mathrm{C}$ or $55^{\circ} \mathrm{C}$ for $5 \mathrm{~s}$ (for $\mathrm{CD} 40$ or $\mathrm{CD} 63$, respectively), and extension at $68^{\circ} \mathrm{C}$ for $25 \mathrm{~s}$.

The BVDV E2 gene was PCR-amplified by using a specific primer set that was designed to amplify a partial E2 fragment that lacked the transmembrane region located at the 3 ' end (33 amino acids). Furthermore, the forward primer was located in the C-terminal hydrophobic region of glycoprotein E1 so that the construct contained 16 amino-acid residues as a leader peptide. The primer sequences were (restriction enzyme sites are underlined): E1 forward primer (Apal + E1), 5'-

GTGGGCCCACCATGGTACAGGGCATCCTATGGCTA-3' and E2 reverse primer (Kpnl + E2), 5'ACGGTACCTCAAGCGAAGTAATCCCGGT-3'. PCR amplifications were performed by using KOD One PCR Master Mix (Toyobo). Reaction mixtures consisted of $40 \mathrm{ng} / 1 \mu \mathrm{L}$ of cDNA, $1 \mu \mathrm{L}$ each of $10 \mu \mathrm{M}$ forward and reverse primers, $5 \mu \mathrm{L}$ of KOD One (Toyobo), and $2 \mu \mathrm{L}$ of sterilized ultrapure water. Amplifications were performed under the following conditions: initial denaturation at $94^{\circ} \mathrm{C}$ for $2 \mathrm{~min}$, followed by 30 cycles of denaturation at $98^{\circ} \mathrm{C}$ for $10 \mathrm{~s}$, annealing at $63^{\circ} \mathrm{C}$ for $5 \mathrm{~s}$, and extension at $68^{\circ} \mathrm{C}$ for $25 \mathrm{~s}$.

Each amplified DNA fragment was enzyme-digested and inserted into pUMVC4a expression vector (Aldevron, South Fargo, ND, USA) to yield pE2, pCD40, or pCD63. The plasmid constructs were verified by DNA sequencing (3500 Genetic Analyzer, Applied Biosystems, Carlsbad, CA, USA). The plasmids were amplified in E. coli DH5a cells and purified by using GenElute HP Endotoxin-Free Plasmid Maxiprep Kit 
(Sigma-Aldrich, St. Louis, MO, USA) according to the manufacturer's instructions. Plasmids were eluted by using nuclease-free ultrapure water and diluted to a concentration of 3 to $10 \mu \mathrm{g} / \mu \mathrm{l}$.

\section{Expression of recombinant BVDV E2 protein in E. coli}

The partial E2 gene (492 bp corresponding to the N-terminal 164 amino acids) of BVDV 1 Nose strain with $\mathrm{N}$-terminal and $\mathrm{C}$-terminal $6 \times$ histidine tags was synthesized by using codon optimization (Eurofins Genomics, Tokyo, Japan). This partial E2 fragment was restriction digested and cloned into pET-41a expression vector (Merck, Darmstadt, Germany). The resulting plasmid pET-41a/E2 was used to transform E. coli BL21 (DE3) cells (Merck). To induce the expression of recombinant BVDV E2 protein (rE2), isopropyl- $\beta$-d-thiogalactopyranoside (final concentration, $1.0 \mathrm{mM}$ ) was added to the culture, which was then incubated for $6 \mathrm{~h}$ at $30^{\circ} \mathrm{C}$. Inclusion bodies containing rE2 were sonicated and solubilized in phosphate-buffered saline (PBS) containing protein denaturants (8 $\mathrm{M}$ urea and $10 \mathrm{mM}$ bmercaptoethanol). rE2 was affinity purified on $\mathrm{Co}^{2+}$-charged TALON resin (Takara Bio) under denaturing conditions, according to the manufacturer's instructions. This was followed by buffer exchange to remove denaturants. The resulting rE2 protein was used as the antigen for ELISA and the production of monoclonal antibodies (mAbs).

\section{Hybridoma production}

BALB/c mice were injected intraperitoneally with rE2 (100 $\mu \mathrm{g} /$ dose); Imject Alum (Thermo Fisher Scientific) was used as an adjuvant. After three booster immunizations at 1-week intervals, splenocytes were harvested and then fused with P3U1 cells by using PEG1500 (Roche Diagnostics, Indianapolis, IN, USA). The resulting hybridomas were grown in RPMI 1640 medium supplemented with $10 \%$ FBS and hypoxanthine-aminopterin-thymidine selection medium supplement (Thermo Fisher Scientific). Hybridomas were chosen on the basis of the reactivity of their culture supernatants against rE2 in ELISAs. We established two hybridoma clones: E2-1a-1 and E2-1a-6. The reactivity of these mAbs was confirmed by Western blot analysis and immunofluorescence staining. Protein G Sepharose 4 Fast Flow (Cytiva, Marlborough, MA, USA) was used to purify the mAbs from the supernatants of hybridomas cultured in Hybridoma-SFM medium (Thermo Fisher Scientific).

\section{Western blot analysis}

The plasmid pE2, pCD40, or pCD63 was transfected into HEK-293T cells by using Polyethylenimine Max (Polysciences, Warrington, PA, USA). At $48 \mathrm{~h}$ after transfection, the cell lysates and culture supernatants were harvested; aliquots of each were boiled in SDS sample buffer (BioRad) and then electrophoresed on $10 \%$ polyacrylamide gels. The separated proteins were electrotransferred onto polyvinylidene difluoride membranes (Merck). After being blocked in PBS containing 5\% skim milk, the membranes were incubated overnight at $4^{\circ} \mathrm{C}$ with $0.1 \mu \mathrm{g} / \mathrm{mL}$ of anti-BVDV E2 mAb (clone E2-1a-1; this study), $0.1 \mu \mathrm{g} / \mathrm{mL}$ of 
anti-CD40 mAb (clone G-12; Santa Cruz Biotechnology, Dallas, TX, USA), $0.1 \mu \mathrm{g} / \mathrm{mL}$ of anti-CD63 mAb (clone: R5G2, MBL, Nagoya, Japan), or $0.1 \mu \mathrm{g} / \mathrm{mL}$ of anti-b-actin (clone AC-15; Sigma-Aldrich) in Solution 1 (Can Get Signal Immunoreaction Enhancer Solution, Toyobo, Osaka, Japan). The overnight incubation was followed by incubation for $1 \mathrm{~h}$ at room temperature with peroxidase-conjugated anti-mouse IgG or anti-rat IgG (dilution, 1:10,000; Jackson ImmunoResearch, West Grove, ME, USA) in Solution 2 (Can Get Signal Immunoreaction Enhancer Solution, Toyobo). Antibody binding was visualized by using ECL Prime Western Blotting Detection Reagent (Cytiva) and a ChemiDoc XRS+ Gel Imaging System (BioRad).

\section{Immunofluorescence staining}

pE2, pCD40, or pCD63 was transfected into CHO-K1 cells by using Polyethylenimine Max (Polysciences). At $24 \mathrm{~h}$ after transfection, cell monolayers in Lab-Tek Chamber Slides (Thermo Fisher Scientific) were fixed with ice-cold methanol at $-30^{\circ} \mathrm{C}$ for $20 \mathrm{~min}$. After they had been blocked in PBS containing $3 \%$ bovine serum albumin, cells were incubated with $1 \mu \mathrm{g} / \mathrm{mL}$ of anti-BVDV E2 mAb (clone E2-1a-6; this study), $1 \mu \mathrm{g} / \mathrm{mL}$ of anti-CD40 mAb (clone G-12; Santa Cruz Biotechnology), or $1 \mu \mathrm{g} / \mathrm{mL}$ of anti-CD63 mAb (clone R5G2; $\mathrm{MBL}$ ) overnight at $4^{\circ} \mathrm{C}$ in PBS containing $3 \%$ bovine serum albumin and then incubated with FITC-conjugated anti-mouse IgG (dilution, 1:200; Jackson ImmunoResarch). Cell nuclei were stained by incubating in $1 \mu \mathrm{g} / \mathrm{mL}$ 4-6-diamidino-2-phenylindole in PBS containing 3\% bovine serum albumin for 15 min at room temperature in the dark. Slides were mounted by using buffered glycerol and then examined by fluorescence microscopy (IX73, Olympus, Tokyo, Japan).

\section{DNA vaccination}

Specific-pathogen-free, age (8 weeks)-matched female BALB/c mice were purchased from Japan SLC (Shizuoka, Japan) and kept under standard conditions. All procedures and animals used in this study were approved by the Iwate University Animal Care and Use Committee (no. A201909).

The mice were anesthetized through intraperitoneal injection of a combination of anesthetics $(0.3 \mathrm{mg} / \mathrm{kg}$ medetomidine, $4.0 \mathrm{mg} / \mathrm{kg}$ midazolam, and $5.0 \mathrm{mg} / \mathrm{kg}$ butorphanol). BALB/c mice $(\mathrm{n}=50)$ were randomly divided into 10 groups; details of the vaccinated groups are shown in Table 1. pCD40 or pCD63 $(0.25,0.5$, 1.0 , or $2.0 \mu \mathrm{g} / \mu \mathrm{L})$ was mixed with pE2 $(2.0 \mu \mathrm{g} / \mu \mathrm{L})$, and $20 \mu \mathrm{L}$ of the resulting plasmid solution was administered intradermally at two different sites. The mice received a booster immunization at 3 weeks after the initial immunization; 2 weeks after the booster immunization, blood samples were collected, and serum was analyzed for humoral immune responses. Splenocytes were harvested at this same time, and BVDV E2 antigen-specific cell proliferation and IFN-g production were evaluated, as described below.

\section{Humoral immune responses}


Virus neutralization titers were determined by using a 96-well microplate assay. Sera were inactivated for $30 \mathrm{~min}$ at $56^{\circ} \mathrm{C}$. Two-fold serially diluted serum samples were mixed with an equal volume of a BVDV 1 (Nose strain) suspension containing $200 \mathrm{TCID}_{50} / 25 \mu \mathrm{L}$; the resulting solutions were placed in microplate wells, and the plate was incubated at $37^{\circ} \mathrm{C}$ for $60 \mathrm{~min}$. After this incubation, bovine fetal muscle cells $\left(10^{5}\right.$ cells/well) were added to each mixture, which was incubated at $37^{\circ} \mathrm{C}$ in a humidified atmosphere of $5 \%$ $\mathrm{CO}_{2}$ in air for 5 days. Each serum dilution was titered twice. The neutralizing antibody titer was expressed as the reciprocal of the highest dilution of the test serum that completely prevented cytopathic effects.

BVDV E2 antigen-specific IgG titers were determined by ELISA. Recombinant E2 protein $(1 \mu \mathrm{g} / \mathrm{mL})$ was immobilized on the well bottoms of Nunc Maxisorp 96-well immunoplates (Thermo Fisher Scientific) by incubating for $60 \mathrm{~min}$. After being blocked with $5 \%$ skim milk in PBS, the plates were incubated with serum from immunized mice (dilution, 1:200), followed by horseradish peroxidase-conjugated anti-mouse $\operatorname{lgG}_{1}$ (dilution, 1:5000; Santa Cruz Biotechnology) and $\operatorname{lgG}_{2 a}$ (dilution, 1:5000; Santa Cruz Biotechnology). The enzymatic reaction was conducted by using 1-Step Ultra TMB-ELISA (Thermo Fisher Scientific). Optical density was measured at a wavelength of $450 \mathrm{~nm}$ on an Infinite 200 PRO multimode plate reader (Tecan Group, Männedorf, Switzerland). These reactions were performed at $37^{\circ} \mathrm{C}$, using a total sample volume of $50 \mu \mathrm{L}$.

\section{Cellular immune responses}

To determine BVDV-specific lymphocyte proliferation, splenocytes were cultured for $48 \mathrm{~h}$ at $37^{\circ} \mathrm{C}$ and $5 \%$ $\mathrm{CO}_{2}$ in the presence of BVDV $1\left(10^{4.5} \mathrm{TCID}_{50}\right.$ per well). All cell cultures were grown in 96-well flat-bottom plates containing $10^{6}$ splenocytes in $200 \mu \mathrm{L}$ RPMI 1640 medium supplemented with $10 \%$ FBS (Thermo Fisher Scientific), 100 units/mL penicillin (Nacalai Tesque), $100 \mu \mathrm{g} / \mathrm{mL}$ streptomycin (Nacalai Tesque), and $2 \mathrm{mM} \mathrm{L-glutamine} \mathrm{(Thermo} \mathrm{Fisher} \mathrm{Scientific).} \mathrm{After} 48 \mathrm{~h}$ of viral stimulation, viable cells were counted by using a WST-8 Cell Proliferation Kit (Dojindo, Kumamoto, Japan) according to the manufacturer's protocol.

To determine BVDV-specific IFN-y production, splenocytes were cultured for $72 \mathrm{~h}$ in the presence of BVDV 1 as described for the proliferation assay; the culture supernatants were then collected and stored at $30^{\circ} \mathrm{C}$. The concentration of IFN- $\gamma$ in the supernatant was measured by using a Mouse IFN- $\gamma$ Uncoated ELISA Kit (Thermo Fisher Scientific) according to the manufacturer's protocol. Optical density was measured at a wavelength of $450 \mathrm{~nm}$ on an Infinite 200 PRO multimode plate reader (Tecan Group).

\section{Statistical analysis}

Serum neutralization antibody titers are presented as geometric means. E2-specific ELISA antibody titers are presented as means. All data were analyzed by using GraphPad Prism 9 (GraphPad software, San Diego, CA, USA) to perform one-way analysis of variance followed by Bonferroni's multiple comparison 
test or the Kruskal-Wallis test followed by Dunn's multiple comparison test. Statistically significant differences were defined as $P<0.05$.

\section{Results}

\section{Construction of expression plasmids}

The coding sequences of a partial E2 (1023 bp) with the C-terminal 16 amino acids of E1, CD40 (870 bp), and CD63 (717 bp) were PCR-amplified and cloned into the pUMVC4a expression vector. The recombinant protein expressed by $\mathrm{pE} 2$, pCD40, or pCD63 was detected by Western blot analysis by using a BVDV E2-, CD40-, or CD63-specific mAb in the cell lysate of HEK-293T cells transfected with each expression vector (Fig. 1a). Because the partial E2 gene lacked the hydrophobic transmembrane region, recombinant E2 protein was detected as a secreted protein in the culture supernatant of $p E 2$-transfected 293T cells (Fig. 1b). In addition, the recombinant protein expressed by pE2, pCD40, or pCD63 was detected in the cytoplasm of transfected $\mathrm{CHO}-\mathrm{K} 1$ cells through immunofluorescence staining with a BVDV E2-, CD40-, or CD63-specific mAb (Fig. 2). These results indicated that pE2, pCD40, and pCD63 expressed recombinant BVDV E2 protein, CD40, and CD63, respectively, in eukaryote cells.

\section{Humoral immune responses}

To investigate the effect of CD40 and CD63 on the humoral immune responses to a BVDV E2 DNA vaccine, virus neutralization titers were compared between the mice that received $\mathrm{pE} 2$ only and those that received $p E 2$ with either $p C D 40$ or pCD63. Neutralizing antibodies were detected in all groups except the mock-immunized group (Fig. 3a), and neutralizing antibody titers were significantly higher in the groups that received pE2 with 10 or $20 \mu \mathrm{g}$ of pCD40 than in those that received pE2 only $(P<0.01)$. In contrast, neutralizing antibody titers did not differ between the group that received $\mathrm{pE} 2$ alone and those that received $\mathrm{pE} 2$ with $\mathrm{pCD} 63$.

BVDV E2-specific $\lg \mathrm{G}_{1}$ and $\lg _{2 a}$ antibody titers were measured through ELISA and compared between mice that received pE2 only and those that received pE2 with pCD40 or pCD63. E2-specific $\lg \mathrm{G}_{1}$ antibodies were detected in all groups except the mock-immunized group (Fig. 3b), and E2-specific $\operatorname{lgG}_{1}$ titers did not differ between the group that received pE2 only and those that received pE2 with pCD40 or pCD63 (Fig. 3b). However, E2-specific $\operatorname{lgG}_{2 a}$ titers were significantly higher in the group that received pE2 with $5 \mathrm{mg}$ of pCD63 than in those that received pE2 only $(P<0.05$; Fig. $3 c)$. In addition, the $\lg \mathrm{G}_{2 a}: \lg \mathrm{Ig}_{1}$ ratio did not differ between the group that received $\mathrm{pE} 2$ only and those that received $\mathrm{pE} 2$ with either pCD40 or pCD63 (Fig. 3d).

\section{Cellular immune responses}


To investigate the effect of CD40 and CD63 on the cellular immune responses to a BVDV E2 DNA vaccine, $B V D V$-specific lymphocyte proliferation was compared between mice that received pE2 only and those that received $\mathrm{pE} 2$ with $\mathrm{p} 40$ or $\mathrm{p} 63$. BVDV-specific lymphocyte proliferation occurred in all other groups apart from the mock-immunized group (Fig. 4a). BVDV-specific proliferation was significantly greater in the group that received pE2 with $5 \mu \mathrm{g}$ or $10 \mu \mathrm{g}$ of pCD40 than in those that received pE2 only $(P<0.01$ and $P<0.0001$, respectively). In addition, BVDV-specific lymphocyte proliferation was greater in the group that received pE2 with $10 \mu \mathrm{g}$ of pCD63 than in those that received pE2 only $(P<0.01)$.

We then compared BVDV-specific IFN-g production between mice that received pE2 only and those that received $p E 2$ with either pCD40 or pCD63. IFN-y production did not differ between the group that received pE2 only and the mock-immunized group (Fig. 4b), but it was significantly higher in the group that received pE2 with $5 \mu \mathrm{g}$ of pCD40 $(P<0.05)$. In addition, IFN- $\gamma$ production was significantly higher in mice that received both pE2 and $10 \mu \mathrm{g}$ of pCD63 than in those that received pE2 only $(P<0.01)$.

\section{Discussion}

In this study, we investigated the effects of CD40 and CD63 on the immune responses to a DNA vaccine against BVDV. First, we constructed plasmids encoding BVDV E2 protein ( $p E 2)$, mouse CD40 (pCD40), or mouse CD63 (pCD63) and used Western blot analysis and immunofluorescence staining to confirm that these plasmids expressed these proteins in cultured cell lines. We then immunized BALB/c mice by using pE2 in combination with, or without, pCD40 or pCD63. The combination of pE2 with pCD40 induced significantly higher neutralizing antibody titers against BVDV than did pE2 only. In addition, pE2 combined with either pCD40 or pCD63 induced significantly greater lymphocyte proliferation and IFN- $\gamma$ production in response to BVDV than did pE2 only.

Our results showed that co-administration of pCD40 enhanced humoral and cellular immune responses to $p E 2$. These results are consistent with those of previous studies. For example, a plasmid encoding CD40 enhanced humoral and T-cell immune responses to a DNA vaccine against foot-and-mouth disease [35]. In another study, a plasmid encoding CD40 enhanced the production of type 2 helper T (Th2) cytokines and antibody responses to a DNA vaccine against H5N1 highly pathogenic avian influenza [33]. These results suggest that co-administration of a plasmid encoding CD40 is a promising means of enhancing humoral and cellular immune responses to DNA vaccines.

In addition, our current study demonstrates that co-administration of pCD63 enhances cellular immune responses to $\mathrm{pE2}$. These results are inconsistent with those of a previous study, in which coadministration of a plasmid encoding CD63 failed to increase cellular immune responses to an OVAencoding plasmid [40]. The reason for this apparent discrepancy is unclear, but it may reflect differences in antigen (BVDV E2 or OVA), plasmid (pUMVC4a or pCl, although both use the same cytomegalovirus promoter), administration route (intradermal or intramuscular), mouse strain (BALB/c or C57BL/Cj), or other experimental conditions. Further studies are needed to clarify whether co-administration of a plasmid encoding CD63 enhances cellular immune responses to DNA vaccines. 
In the current study, we did not observe dose-dependency in the adjuvant effect due to pCD40 or pCD63. For example, the highest dose $(40 \mu \mathrm{g})$ of neither PCD 40 or pCD63 enhanced the immune responses to pE2, whereas 10 or $20 \mu \mathrm{g}$ of pCD40 induced the greatest neutralizing antibody responses and $10 \mu \mathrm{g}$ of pCD63 induced the greatest lymphocyte proliferation and IFN- $\gamma$ responses. These results are in harmony with those of previous reports, in which excess doses of plasmids decreased expression levels of foreign genes $[41,42]$. In this study, the excess dose $(40 \mu \mathrm{g})$ of pCD40 or pCD63 may have hampered the expression of either $\mathrm{CD} 40$ or $\mathrm{CD} 63$, respectively, or it may have competitively diminished E2 expression from pE2. The optimal dose of a plasmid encoding CD40 or CD63 for use as a DNA vaccine adjuvant will need to be determined in the target animal species.

Administration of pE2 induced $\operatorname{lgG}_{1}$ antibody responses, and co-administration of pCD40 or pCD63 did not significantly change the $\operatorname{lgG}_{2 a}: \operatorname{lgG}_{1}$ ratio. This result is consistent with those of previous studies, in which the administration of DNA vaccines encoding secreted antigen induced predominantly lgG1 antibody production $[43,44]$. In contrast, a plasmid encoding BVDV E2 dominantly induced IgG2a antibody responses $[45,46]$. The reason for this apparent discrepancy is unknown. It has been reported that the route of administration of DNA vaccines affects Th1/Th2 bias: intradermal administration of DNA vaccines induces Th2 responses, whereas intramuscular administration induces Th1 responses [47, 48]. However, our current and preliminary studies showed that both intradermal or intramuscular administration of pE2 predominantly induced IgG1 antibody responses (data not shown), suggesting that a secreted form of E2 antigen induces an IgG1 response regardless of the route of administration.

In conclusion, the results that we have presented indicate that co-administration of a plasmid encoding CD40 or CD63 enhances humoral and cellular immune responses to a DNA vaccine encoding BVDV E2 protein. Our current results further suggest that these adjuvant plasmids have the potential to compensate for the weak immunogenicity of DNA vaccines-not only for BVDV but also for various other applications, including other infectious diseases, therapy of cancer, allergies, and autoimmunity.

\section{Declarations}

Acknowledgments We thank Ikunori Naito, DVM (Graduate School of Veterinary Sciences, Gifu University) for helpful discussion.

Funding This research was supported in part by the Platform Project for Supporting Drug Discovery and Life Science Research (Basis for Supporting Innovative Drug Discovery and Life Science Research [BINDS]) from Japan Agency for Medical Research and Development (AMED) under grant number JP21am0101078 (support number 2399).

Conflict of Interest The authors declare that no conflict of interest exists.

Ethics statement This study was conducted according to the applicable institutional, national, and international guidelines for the care and use of animals and was approved by the Iwate University Animal Care and Use Committee (no. A201909). 


\section{References}

1. Simmonds P, Becher P, Collett MS, Gould EA, Heinz FX, Meyers G, Monath T, Pletnev A, Rice CM, Stiasny K, Thiel H-J, Weiner A, Bukh J (2011) Family Flaviviridae. In: King AM, Lefkowitz E, Adams MJ, Carstens EB (eds) Virus taxonomy: Ninth report of the International Committee on Taxonomy of Viruses. Elsevier, San Diego, pp 1003-1020

2. Smith DB, Meyers G, Bukh J, Gould EA, Monath T, Scott Muerhoff A, Pletnev A, Rico-Hesse R, Stapleton JT, Simmonds P, Becher P (2017) Proposed revision to the taxonomy of the genus Pestivirus, family Flaviviridae. J Gen Virol 98:2106-2112

3. Walz PH, Grooms DL, Passler T, Ridpath JF, Tremblay R, Step DL, Callan RJ, Givens MD (2010) Control of bovine viral diarrhea virus in ruminants. J Vet Intern Med 24:476-486

4. World Organizaitn of Animal Health (OIE) (2018) Bovine viral diarrhoea. Manual of diagnostic tests and vaccines for terrestrial animals. World Organization of Animal Health (OIE), Paris, pp 1075-1096

5. Lanyon SR, Hill FI, Reichel MP, Brownlie J (2014) Bovine viral diarrhoea: pathogenesis and diagnosis. Vet J 199:201-209

6. McClurkin A, Littledike E, Cutlip R, Frank G, Coria M, Bolin S (1984) Production of cattle immunotolerant to bovine viral diarrhea virus. Can J Comp Med 48:156

7. Iotti B, Valdano E, Savini L, Candeloro L, Giovannini A, Rosati S, Colizza V, Giacobini M (2019) Farm productive contexts and the dynamics of bovine viral diarrhea (BVD) transmission. Prev Vet Med 165:23-33

8. Hessman BE, Fulton RW, Sjeklocha DB, Murphy TA, Ridpath JF, Payton ME (2009) Evaluation of economic effects and the health and performance of the general cattle population after exposure to cattle persistently infected with bovine viral diarrhea virus in a starter feedlot. Am J Vet Res 70:73-85

9. Sekiguchi S, Presi P, Omori R, Staerk K, Schuppers M, Isoda N, Yoshikawa Y, Umemura T, Nakayama H, Fujii Y, Sakoda Y (2018) Evaluation of bovine viral diarrhoea virus control strategies in dairy herds in Hokkaido, Japan, using stochastic modelling. Transbound Emerg Dis 65:e135-e144

10. Platt R, Coutu C, Meinert T, Roth JA (2008) Humoral and T cell-mediated immune responses to bivalent killed bovine viral diarrhea virus vaccine in beef cattle. Vet Immunol Immunopathol 122:8-15

11. Platt R, Burdett W, Roth JA (2006) Induction of antigen-specific T-cell subset activation to bovine respiratory disease viruses by a modified-live virus vaccine. Am J Vet Res 67:1179-1184

12. Platt R, KesI L, Guidarini C, Wang C, Roth JA (2017) Comparison of humoral and T-cell-mediated immune responses to a single dose of Bovela ${ }^{\circledR}$ live double deleted BVDV vaccine or to a field BVDV strain. Vet Immunol Immunopathol 187:20-27

13. Prazeres DMF, Monteiro GA (2014) Plasmid Biopharmaceuticals. Microbiol Spectr 2

14. Hobernik D, Bros M (2018) DNA Vaccines-How Far From Clinical Use? Int J Mol Sci 19:3605

15. Fioretti D, lurescia S, Rinaldi M (2014) Recent advances in design of immunogenic and effective naked DNA vaccines against cancer. Recent Pat Anticancer Drug Discov 9:66-82 
16. Scheiblhofer S, Thalhamer J, Weiss R (2018) DNA and mRNA vaccination against allergies. Pediatr Allergy Immunol 29:679-688

17. Zhang N, Nandakumar KS (2018) Recent advances in the development of vaccines for chronic inflammatory autoimmune diseases. Vaccine 36:3208-3220

18. Maslow JN (2017) Vaccines for emerging infectious diseases: Lessons from MERS coronavirus and Zika virus. Hum Vaccin Immunother 13:2918-2930

19. Corbeil S, Kurath G, Lapatra SE (2000) Fish DNA vaccine against infectious hematopoietic necrosis virus: efficacy of various routes of immunisation. Fish Shellfish Immunol 10:711-723

20. Kutzler MA, Weiner DB (2008) DNA vaccines: ready for prime time? Nature Reviews Genetics 9:776788

21. Draghia-Akli R, Fiorotto ML, Hill LA, Malone PB, Deaver DR, Schwartz RJ (1999) Myogenic expression of an injectable protease-resistant growth hormone-releasing hormone augments long-term growth in pigs. Nat Biotechnol 17:1179-1183

22. Atherton MJ, Morris JS, McDermott MR, Lichty BD (2016) Cancer immunology and canine malignant melanoma: A comparative review. Vet Immunol Immunopathol 169:15-26

23. Dauphin G, Zientara S (2007) West Nile virus: Recent trends in diagnosis and vaccine development. Vaccine 25:5563-5576

24. Weiland E, Stark R, Haas B, Rümenapf T, Meyers G, Thiel H-J (1990) Pestivirus glycoprotein which induces neutralizing antibodies forms part of a disulfide-linked heterodimer. J Virol 64:3563-3569

25. Shope Jr R, Muscoplat CC, Chen AW, Johnson D (1976) Mechanism of protection from primary bovine viral diarrhea virus infection. I. The effects of dexamethasone. Can J Comp Med 40:355

26. Howard CJ, Clarke MC, Brownlie J (1989) Protection against respiratory infection with bovine virus diarrhoea virus by passively acquired antibody. Vet Microbiol 19:195-203

27. Peters AL, Stunz LL, Bishop GA (2009) CD40 and autoimmunity: The dark side of a great activator. Semin Immunol 21:293-300

28. Bishop GA (2004) The multifaceted roles of TRAFs in the regulation of B-cell function. Nature Reviews Immunology 4:775-786

29. Carlring J, Barr TA, McCormick AL, Heath AW (2004) CD40 antibody as an adjuvant induces enhanced T cell responses. Vaccine 22:3323-3328

30. Barr TA, Carlring J, Heath AW (2005) CD40 antibody as a potent immunological adjuvant: CD40 antibody provides the CD40 signal to B cells, but does not substitute for $\mathrm{T}$ cell help in responses to TD antigens. Vaccine 23:3477-3482

31. Tellander AC, Michaëlsson E, Brunmark C, Andersson M (2000) Potent Adjuvant Effect by Anti-CD40 in Collagen-induced Arthritis. Enhanced Disease is Accompanied by Increased Production of Collagen Type-II Reactive IgG2a and IFN-y. J Autoimmun 14:295-302

32. Ninomiya A (2002) Intranasal administration of a synthetic peptide vaccine encapsulated in liposome together with an anti-CD40 antibody induces protective immunity against influenza $A$ virus 
in mice. Vaccine 20:3123-3129

33. Chen Q, Zhu G, Wang R, Zhang J, He G (2014) Adjuvant effect of CD40 on H5N1 DNA vaccine in mice. Arch Virol 159:1359-1364

34. Sicard T, Kassardjian A, Julien J-P (2020) B cell targeting by molecular adjuvants for enhanced immunogenicity. Expert Review of Vaccines 19:1023-1039

35. Xu H, Zhao G, Huang X, Ding Z, Wang J, Wang X, Cheng Y, Kang Y, Wang B (2010) CD40-expressing plasmid induces anti-CD40 antibody and enhances immune responses to DNA vaccination. J Gene Med 12:97-106

36. Metzelaar MJ, Wijngaard PL, Peters PJ, Sixma JJ, Nieuwenhuis HK, Clevers HC (1991) CD63 antigen. A novel lysosomal membrane glycoprotein, cloned by a screening procedure for intracellular antigens in eukaryotic cells. J Biol Chem 266:3239-3245

37. Petersen SH, Odintsova E, Haigh TA, Rickinson AB, Taylor GS, Berditchevski F (2011) The role of tetraspanin CD63 in antigen presentation via MHC class II. Eur J Immunol 41:2556-2561

38. Engering A, Kuhn L, Fluitsma D, Hoefsmit E, Pieters J (2003) Differential post-translational modification of CD63 molecules during maturation of human dendritic cells. Eur J Biochem $270: 2412-2420$

39. Pfistershammer K, Majdic O, Stöckl J, Zlabinger G, Kirchberger S, Steinberger P, Knapp W (2004) CD63 as an activation-linked T cell costimulatory element. J Immunol 173:6000-6008

40. Kanuma T, Yamamoto T, Kobiyama K, Moriishi E, Masuta Y, Kusakabe T, Ozasa K, Kuroda E, Jounai N, Ishii KJ (2017) CD63-Mediated Antigen Delivery into Extracellular Vesicles via DNA Vaccination Results in Robust CD8+ T Cell Responses. J Immunol 198:4707-4715

41. Schulte PM, Powers DA, Schartl M (1998) Efficient gene transfer into Xiphophorus muscle and melanoma by injection of supercoiled plasmid DNA. Mol Mar Biol Biotechnol 7:241-247

42. Gómez-Chiarri M, Livingston S, Muro-Cacho C, Sanders S, Levine R (1996) Introduction of foreign genes into the tissue of live fish by direct injection and particle bombardment. Dis Aquat Organ 27:512

43. Rush C, Mitchell T, Garside P (2002) Efficient Priming of CD4+and CD8+T Cells by DNA Vaccination Depends on Appropriate Targeting of Sufficient Levels of Immunologically Relevant Antigen to Appropriate Processing Pathways. J Immunol 169:4951-4960

44. Haddad D, Liljeqvist S, Ståhl S, Perlmann P, Berzins K, Ahlborg N (1998) Differential induction of immunoglobulin $\mathrm{G}$ subclasses by immunization with DNA vectors containing or lacking a signal sequence. Immunol Lett 61:201-204

45. Nobiron I, Thompson I, Brownlie J, Collins ME (2000) Co-administration of IL-2 enhances antigenspecific immune responses following vaccination with DNA encoding the glycoprotein E2 of bovine viral diarrhoea virus. Vet Microbiol 76:129-142

46. Nobiron I, Thompson I, Brownlie J, Collins ME (2001) Cytokine adjuvancy of BVDV DNA vaccine enhances both humoral and cellular immune responses in mice. Vaccine 19:4226-4235 
47. Pertmer TM, Roberts TR, Haynes JR (1996) Influenza virus nucleoprotein-specific immunoglobulin G subclass and cytokine responses elicited by DNA vaccination are dependent on the route of vector DNA delivery. J Virol 70:6119-6125

48. McCluskie MJ, Millan CLB, Gramzinski RA, Robinson HL, Santoro JC, Fuller JT, Widera G, Haynes JR, Purcell RH, Davis HL (1999) Route and Method of Delivery of DNA Vaccine Influence Immune Responses in Mice and Non-Human Primates. Mol Med 5:287-300

\section{Tables}

Due to technical limitations, table 1 is only available as a download in the Supplemental Files section.

\section{Figures}

(a)

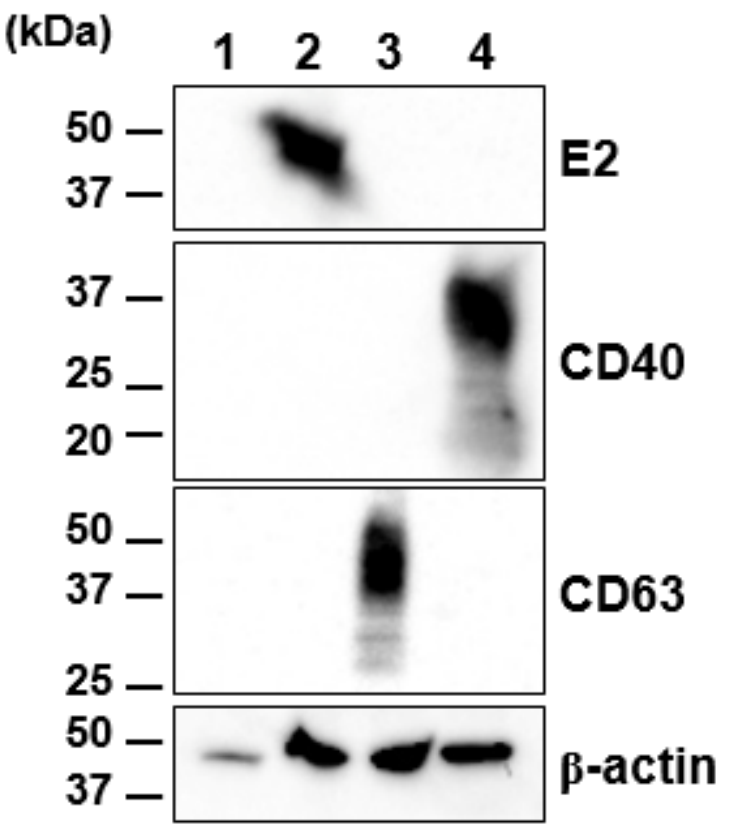

(b)

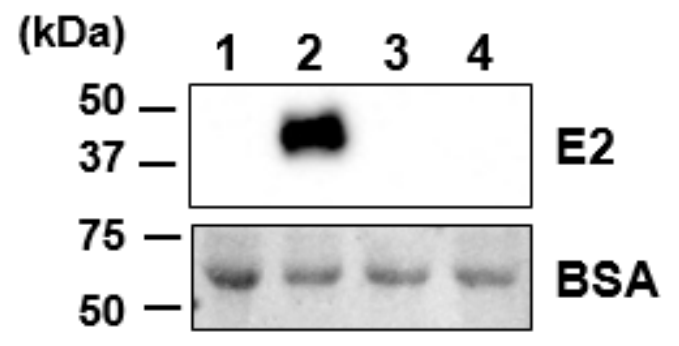

\section{Figure 1}

In vitro expression of bovine viral diarrhea virus (BVDV) E2, mouse CD40, and mouse CD63 according to Western blot analysis. HEK-293T cells were transfected with pUMVC4a (lane 1), pE2 (lane 2), pCD40 (lane 3), or pCD63 (lane 4). (a) Cell lysates (approximately $10 \mathrm{mg} /$ lane) were electrophoresed through 10\% polyacrylamide gels under reducing conditions and transferred onto a PVDF membrane. The membrane was stained with anti-E2 $(0.1 \mu \mathrm{g} / \mathrm{mL})$, anti-CD40 $(0.1 \mu \mathrm{g} / \mathrm{mL})$, anti-CD63 $(0.1 \mu \mathrm{g} / \mathrm{mL})$, or anti- $\beta$-actin $(0.1$ 
$\mu \mathrm{g} / \mathrm{mL}$ ) mAb. (b) Cell culture supernatants (5 $\mathrm{mL}$ per lane) were electrophoresed through $10 \%$ polyacrylamide gels under reducing conditions and transferred onto a PVDF membrane. The membrane was stained with anti-E2 $\mathrm{mAb}(0.1 \mu \mathrm{g} / \mathrm{mL})$ or Ponceau S. BSA, bovine serum albumin
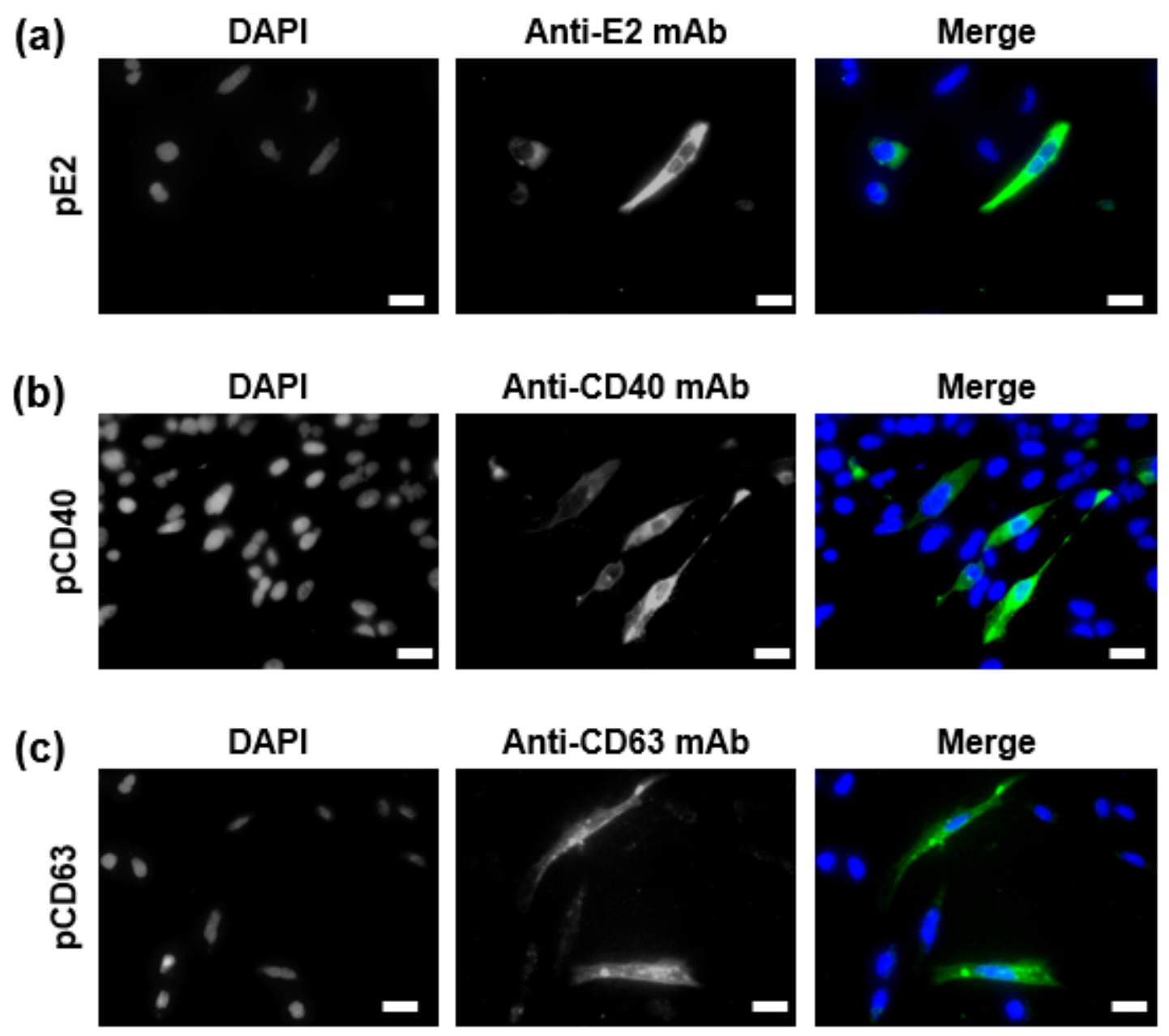

Figure 2

In vitro expression of BVDV E2, mouse CD40, and mouse CD63 according to immunofluorescence staining. CHO-K1 cells were transfected with pE2 (a), pCD40 (b), or pCD63 (c) and stained with anti-E2 (1 $\mu \mathrm{g} / \mathrm{mL})$, anti-CD40 $(1 \mu \mathrm{g} / \mathrm{mL})$, or anti-CD63 $(1 \mu \mathrm{g} / \mathrm{mL}) \mathrm{mAb}$ and FITC-conjugated secondary Abs. Nuclei were stained with DAPI. Scale bar, $20 \mathrm{~mm}$ 

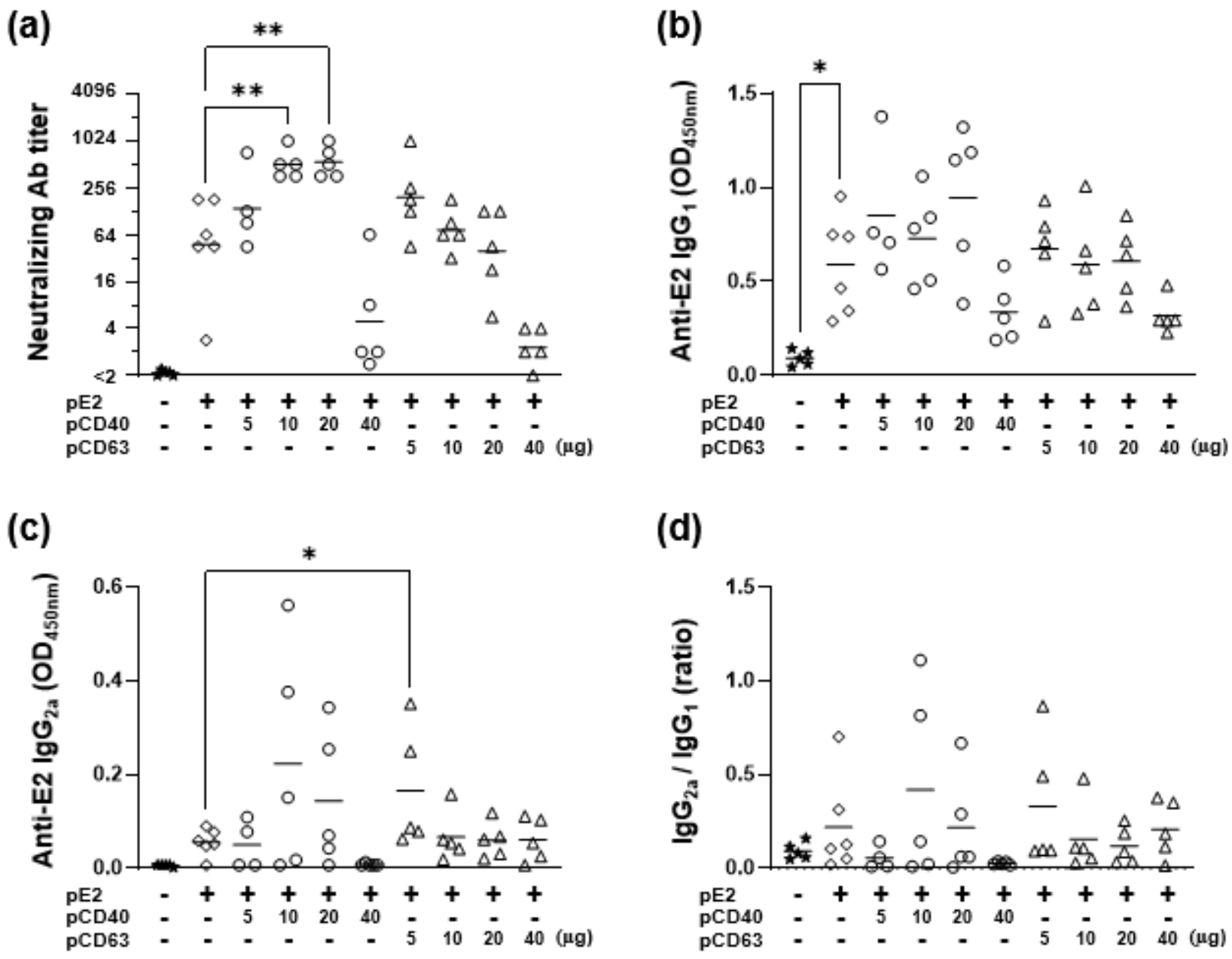

\section{Figure 3}

Adjuvant effects of CD40 and CD63 on humoral immune responses to a BVDV E2 DNA vaccine. BALB/C mice were intradermally immunized twice with pE2 in combination with, or without, pCD40 or pCD63 (3 weeks between doses). (a) Virus neutralizing antibody titers. Horizontal bars indicate geometric mean values. (b) Anti-E2 IgG 1 titers. Horizontal bars indicate mean values. (c) Anti-E2 $\operatorname{lgG}_{2 a}$ titers. Horizontal bars indicate mean values. (d) $\operatorname{lgG}_{1}: \operatorname{lgG}_{2 a}$ ratio. Horizontal bars indicate mean values. Differences between groups were assessed by one-way analysis of variance followed by Bonferroni's multiple comparison test, $\left.P<0.05{ }^{(}\right)$and $P<0.01{ }^{(* *}$. The presented data are representative of two independent

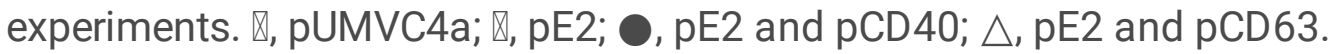


(a)

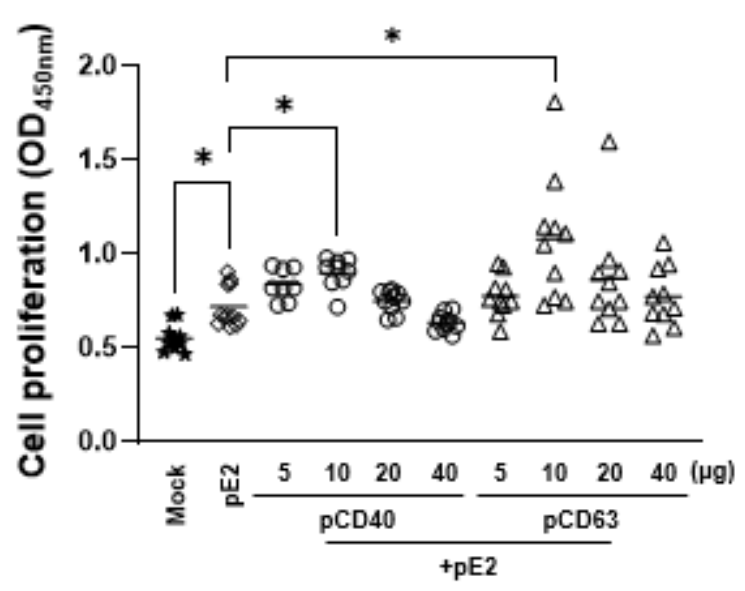

(b)

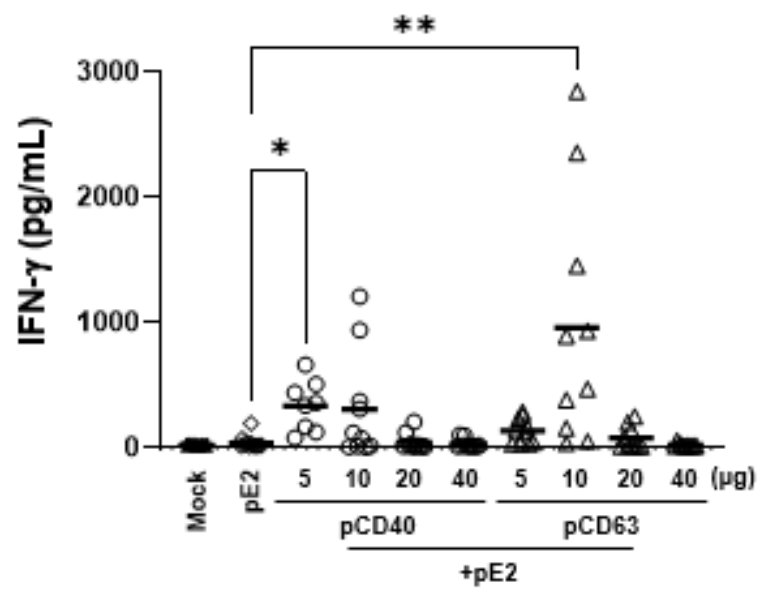

\section{Figure 4}

Adjuvant effects of CD40 and CD63 on cellular immune responses to a BVDV E2 vaccine. BALB/c mice were immunized intradermally twice with pE2 in combination with, or without, pCD40 or pCD63 (3 weeks between doses). (a) BVDV-specific lymphocyte proliferation. Splenocytes were stimulated with BVDV for $48 \mathrm{~h}$, after which WST-8 was added and the absorbance at a wavelength of $450 \mathrm{~nm}$ was measured.

Horizontal bars indicate mean values. Differences between groups were assessed by one-way analysis of variance followed by Bonferroni's multiple comparison test. (b) BVDV-specific interferon (IFN)- $\gamma$ production. Splenocytes were stimulated with BVDV for $72 \mathrm{~h}$. IFN-y in the cell culture supernatants were measured through ELISA. Horizontal bars indicate mean values. Differences between groups were assessed by using the Kruskal-Wallis test followed by Dunn's multiple comparison test, $P<0.05\left(^{*}\right)$ and

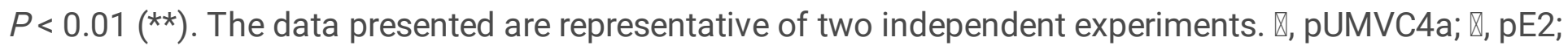
-, $\mathrm{pE} 2$ and $\mathrm{pCD} 40 ; \triangle, \mathrm{pE} 2$ and $\mathrm{pCD} 63$.

\section{Supplementary Files}

This is a list of supplementary files associated with this preprint. Click to download.

- Table1Leng.xlsx 